$$
\begin{aligned}
& \text { تأثير الحجم الحبيبي في بعض الخواص الميكاتيكية لمواد متر اكبة بوليميرية متدرجة } \\
& \text { وظيفياً مصنعة بطريقة الطرد المركزي المئي } \\
& \text { أحمد أكرم عبد الله ج جامعة الموصل/ كلية الهندسة / قسم الهندة الميكانيكية.عواد هلوش خضر }
\end{aligned}
$$

\title{
الخلاصة
}

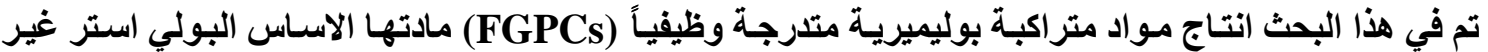

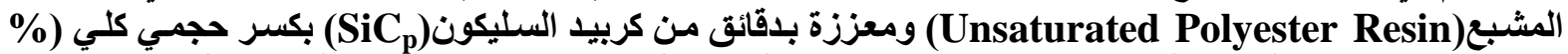

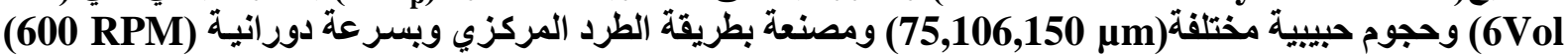

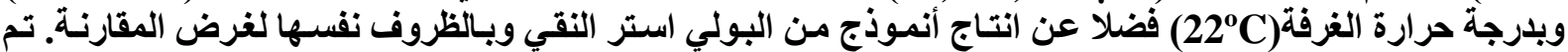

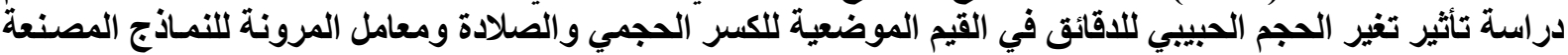

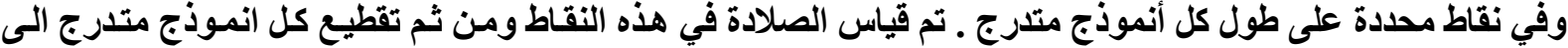

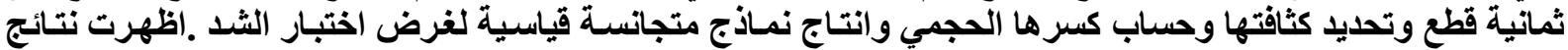

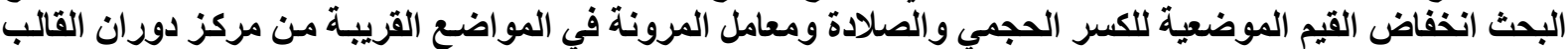

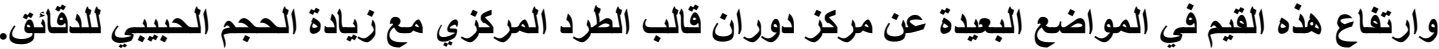

\section{Effect of Particle Size on Some Mechanical Properties of Functionally Graded Polymeric Matrix Composite Produced by Centrifugal Casting}

\author{
Ahmed Akram Abdullah
}

Awad Hallosh Khidhir

Assistant Professor

University of Mosul/Collage of Eng./Mech. Eng. Dep.

\begin{abstract}
In this research a functionally graded polymeric composites (FGPCs) were produced using centrifugal casting method . These composites were fabricated from unsaturated polyester resin as a matrix reinforced with silicon carbide particles $\left(\mathrm{SiC}_{\mathbf{p}}\right)$ of different particle size $(75,106,150 \mu \mathrm{m})$ and $(6 \mathrm{vol} \%)$ bulk volume fraction, using $(600$ RPM) mold rotational speeds . The aim of the present research was to study the effect of $\left(\mathrm{SiC}_{\mathrm{p}}\right)$ particle size on local values of volume fraction, hardness and Young modulus at specific points along the graded samples. Hardness was measured at these points then graded samples were cut to eight portions . Density , volume fraction were calculated, then standard homogenous samples of constant but different volume fractions were manufactured. Results show that local values of volume fraction, hardness and young modulus decreased in nearby positions of the center of rotation and increased in positions far away from the center of rotation.
\end{abstract}

Key words: Functionally graded polymeric Matrix composite, Unsaturated Polyester Resin, hardness, modulus of elasticity. 


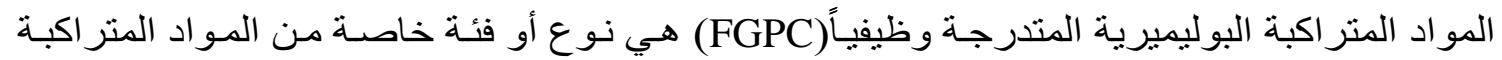

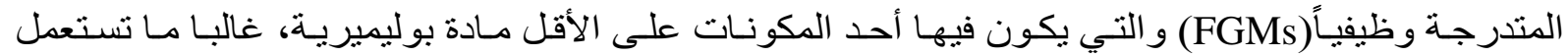

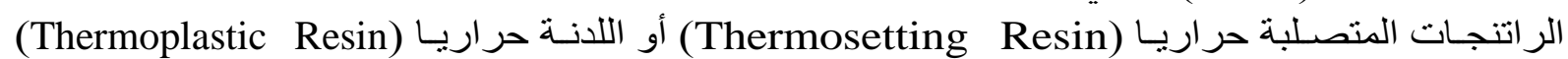

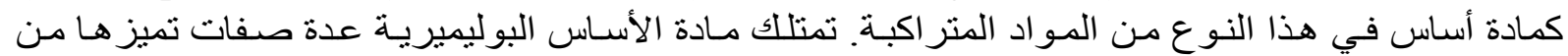

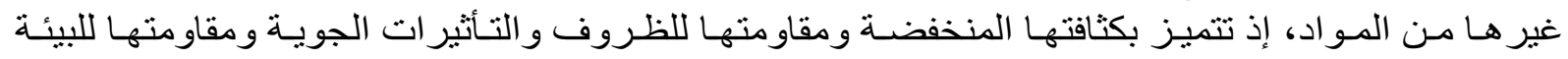

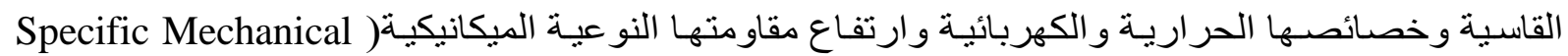

.[1] (Strength

حيث قام الباحث(R.J.Butcher,1998) بإنتاج مو اد متر اكبة بوليميرية متدرجة وظيفياً مادتها الأساس

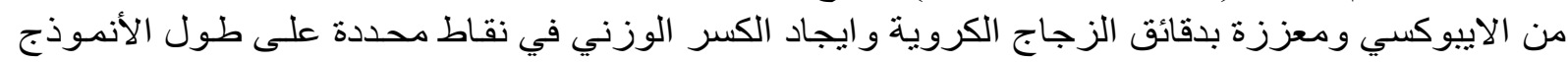

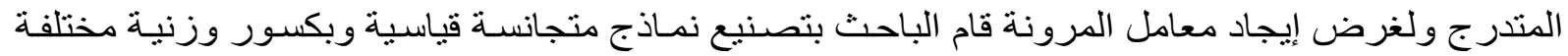

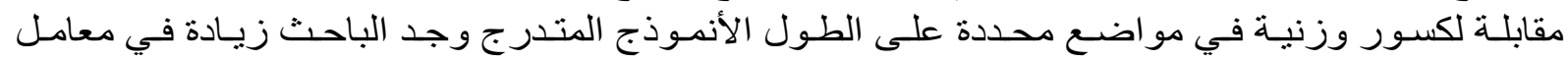

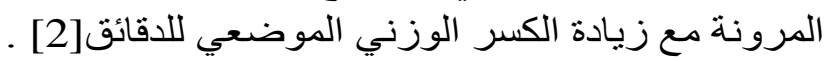
درس الباحث(Saad M. Elia,2011) تأثير اضافة مسحوق من عقيدات البحر(Sea Nodules) بأحجام

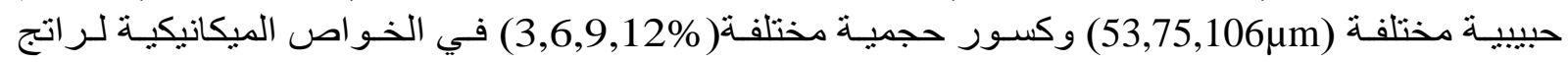

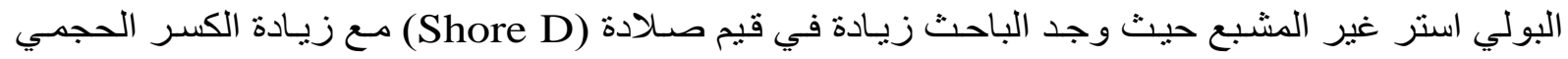

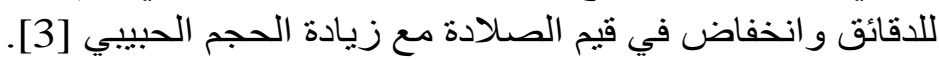

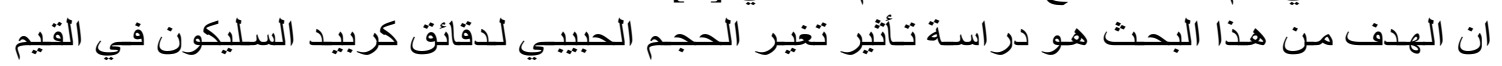
الموضعية للصلادة ومعامل المرونة.

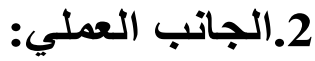

تم استخدام راتنج البولي استر غير المشـبع(Unsaturated Polyester Resin) و المصنّع من قبـل

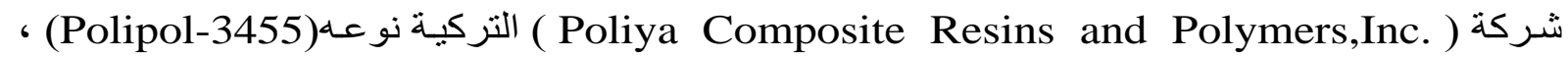

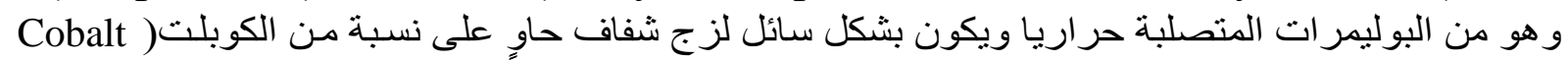

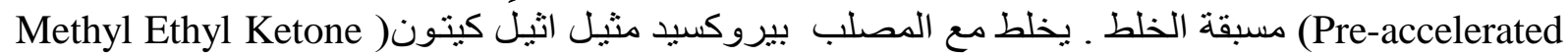
Akpa Organic Peroxides, Initiators \& Paint المنتج من قبل شركة) (Peroxide MEKP

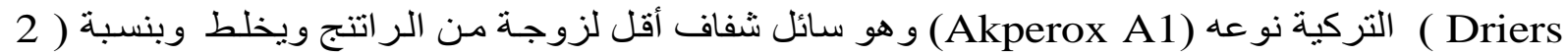

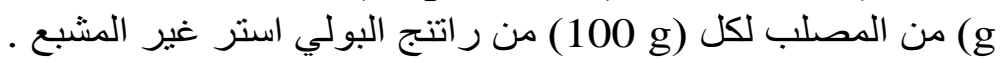

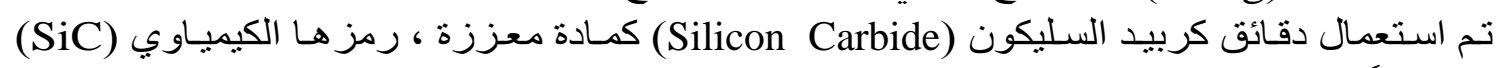
وتعرف تجارياً باسم كربورندم (Carborundum) و الثكل (1) يوضـح صسورة مجهريـة للدقائق المستعملة في البحث.
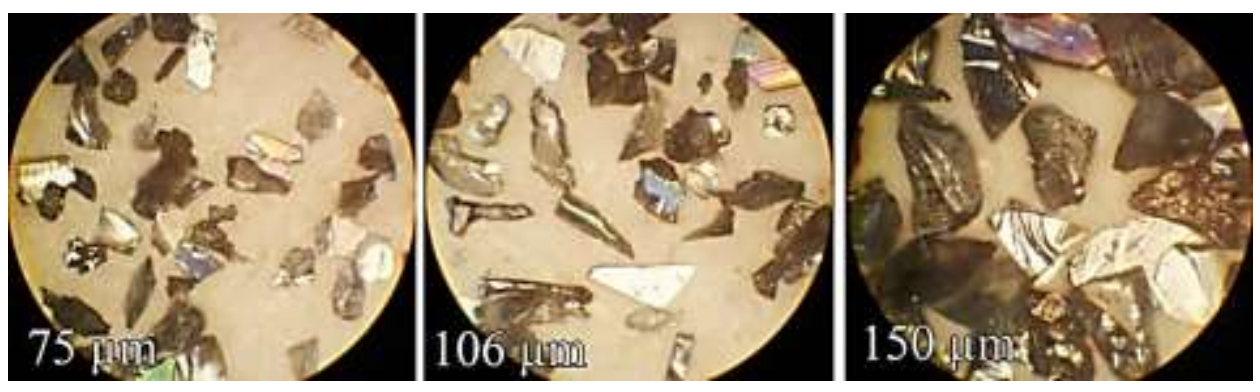

الثكل(1): دقائق كربيد السليكون المستعملة في البحث بأحجامها الثلاثة (X100). 


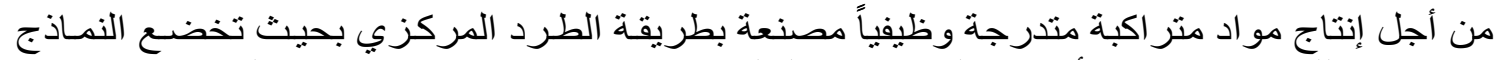

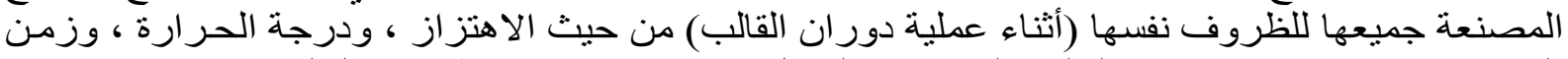

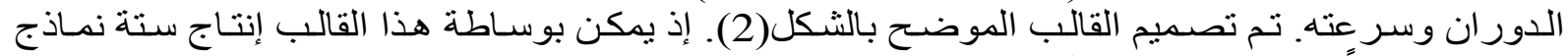

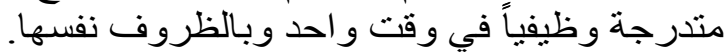

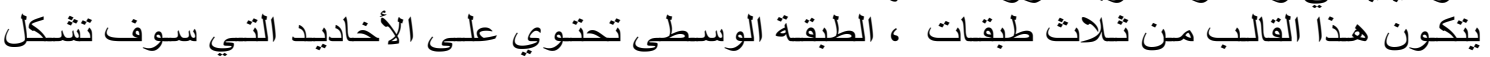

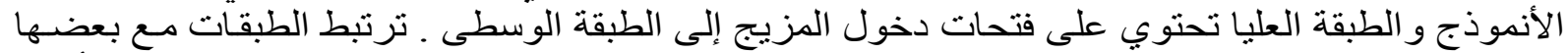

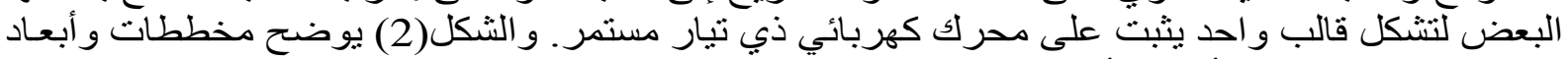

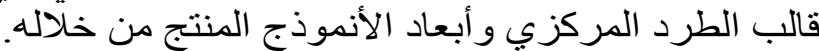

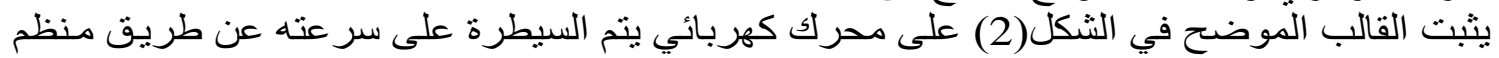

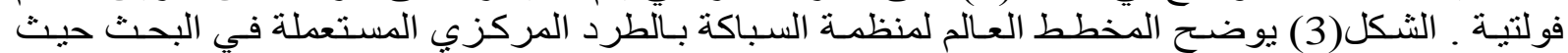

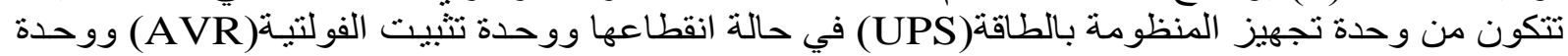

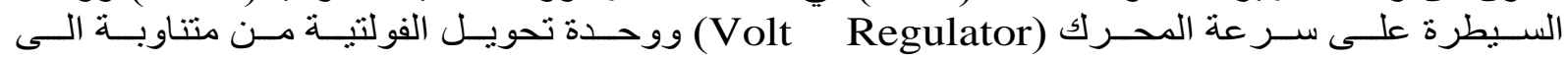

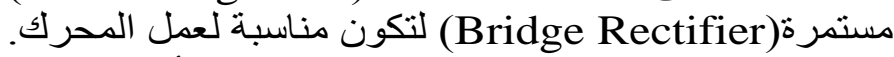

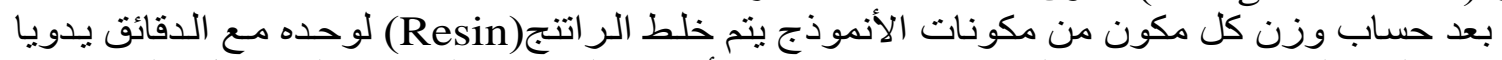

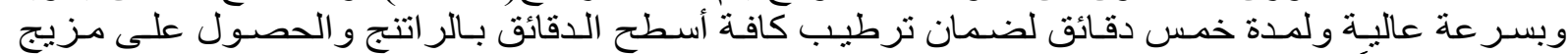

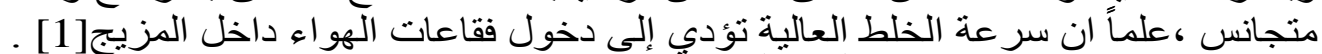

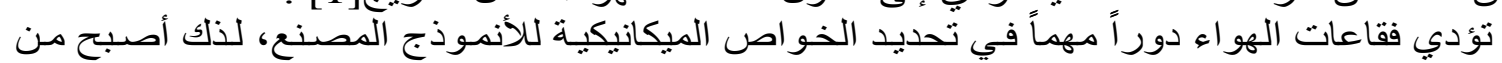

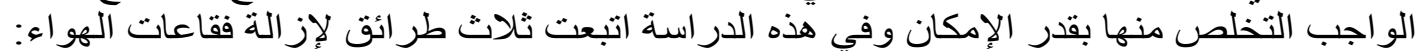

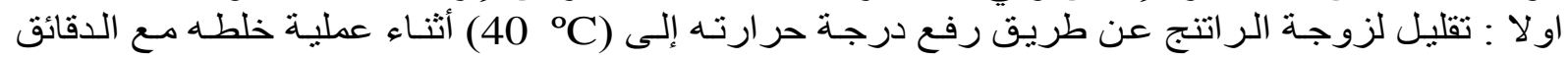

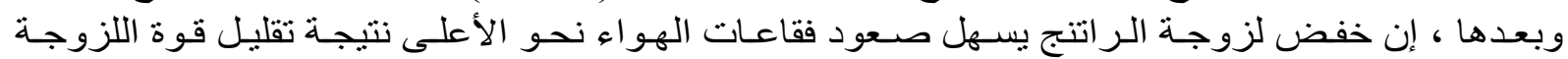

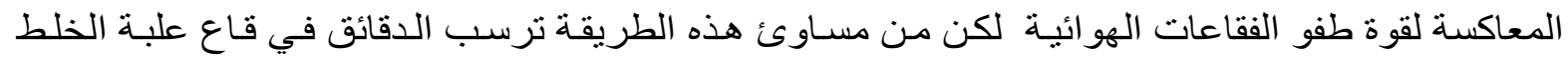
و ويمكن حل هذه المشكلة برفع اللزوجة بعد خروج فقاعات الهو اء و إعادة الخلط ولكن ببطيء شديد.

ثانيا: بعد إكمال خلط الر اتنج بالدقائق وتقليل لزوجة الر اتنج توضع علب الخلط في و وعاء محكم الغلق ويتم

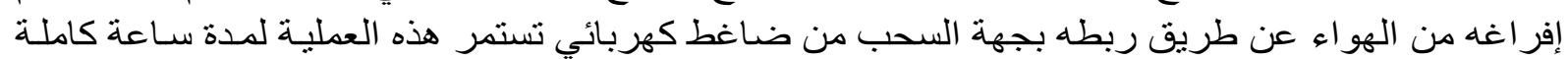
تبقى فيها علب الخلط الحاوية على الر اتتج و الدقائق داخل هذا الو عاء و الثكل(4) يوضنح الأسلوب المتبع.

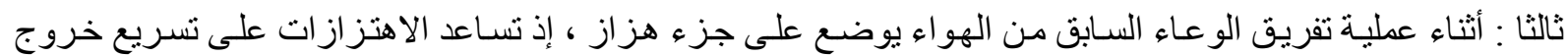

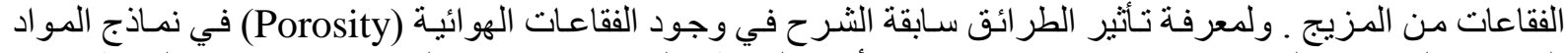

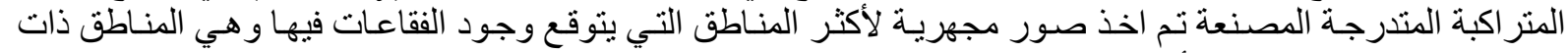

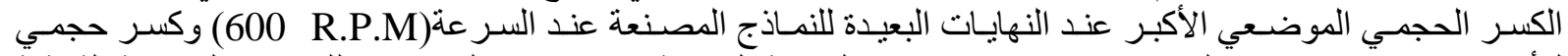

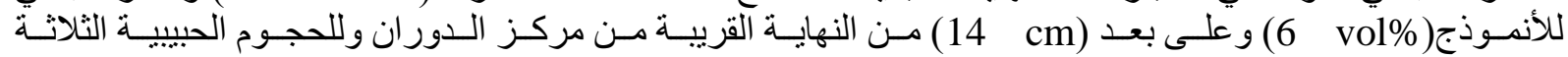

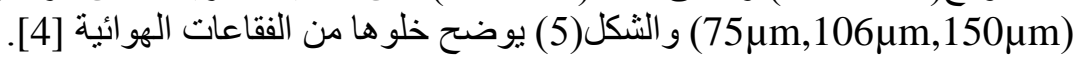

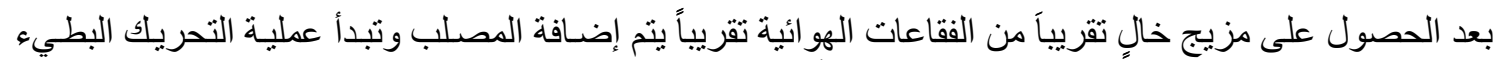

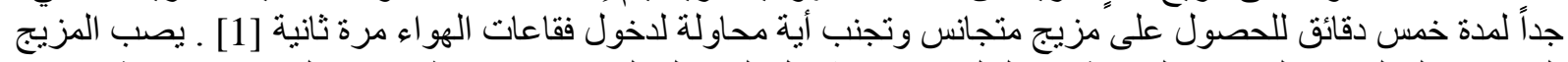

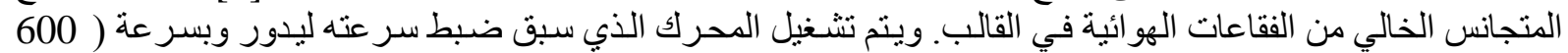

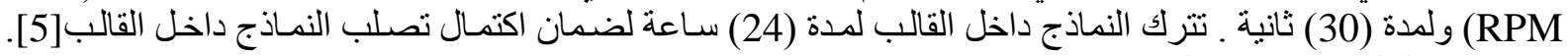

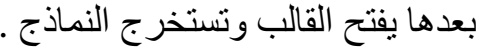

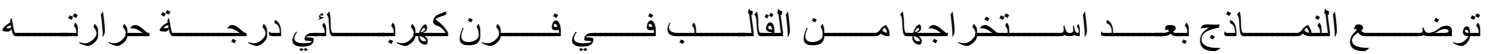

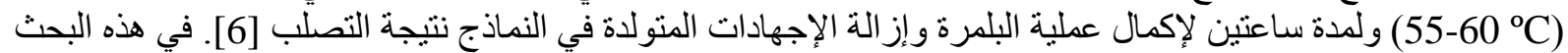

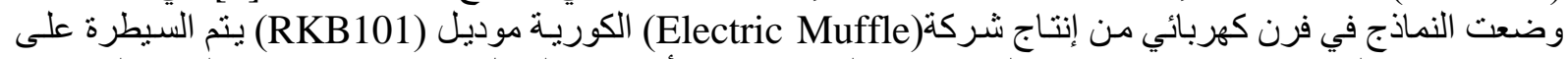

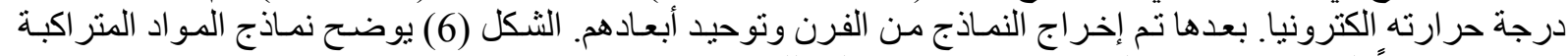

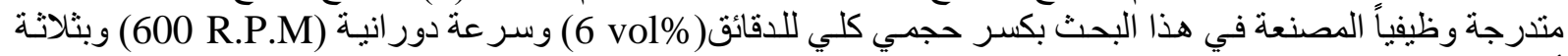
أحجام حبييية مختلفة لدقائق كربيد السليكون هي (75,106,150بm). 


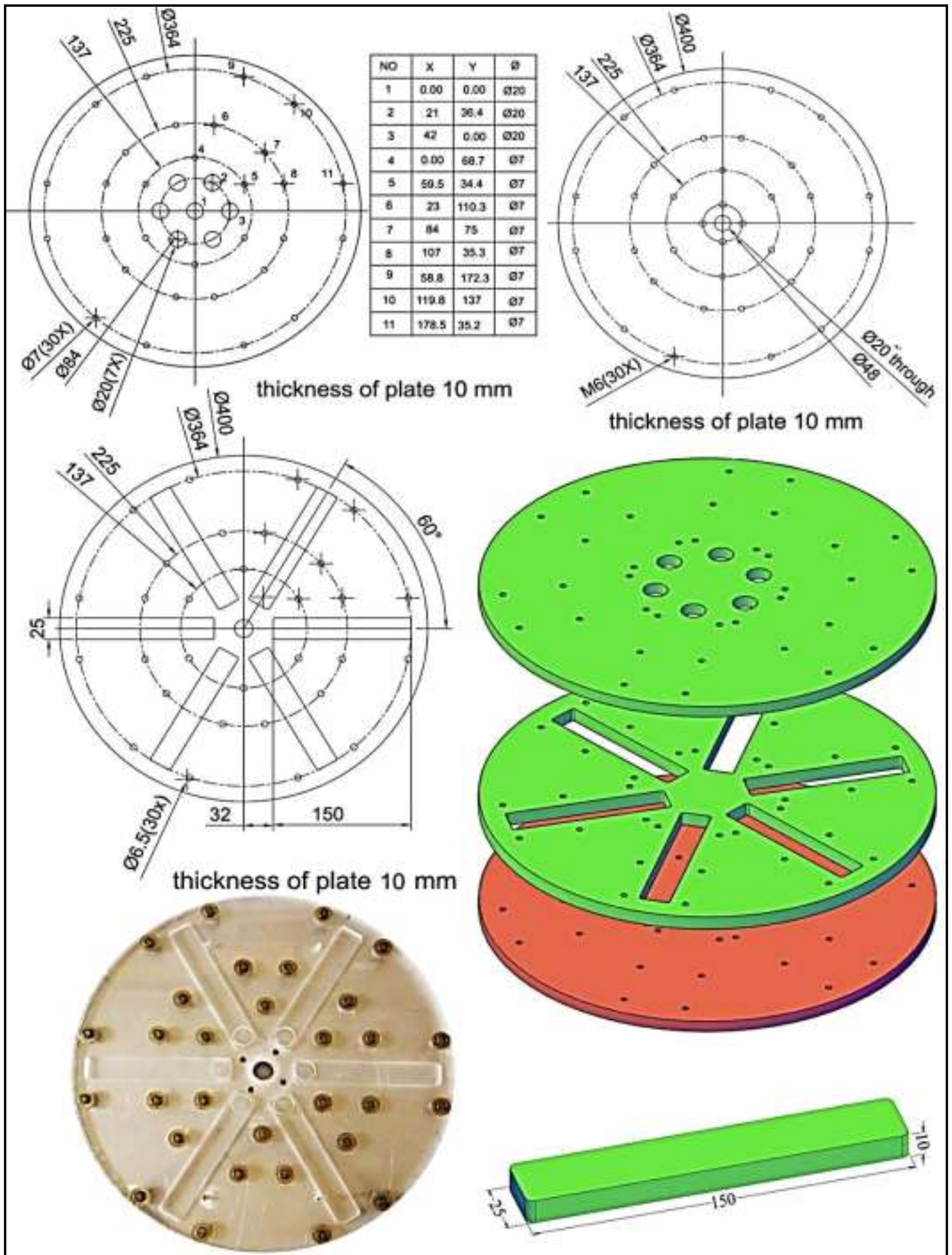

الثكل(2):قالب الطرد المركزي و الأنموذج المصنع في البحث الحالي(mm).

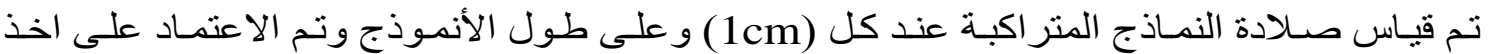

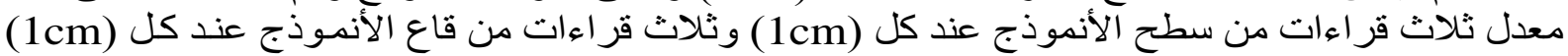

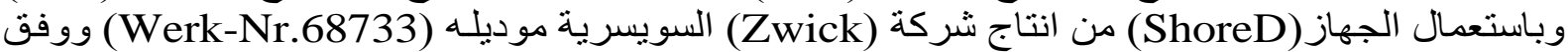

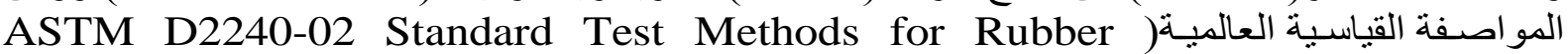
. [8][7]‘(Property Durometer Hardness 


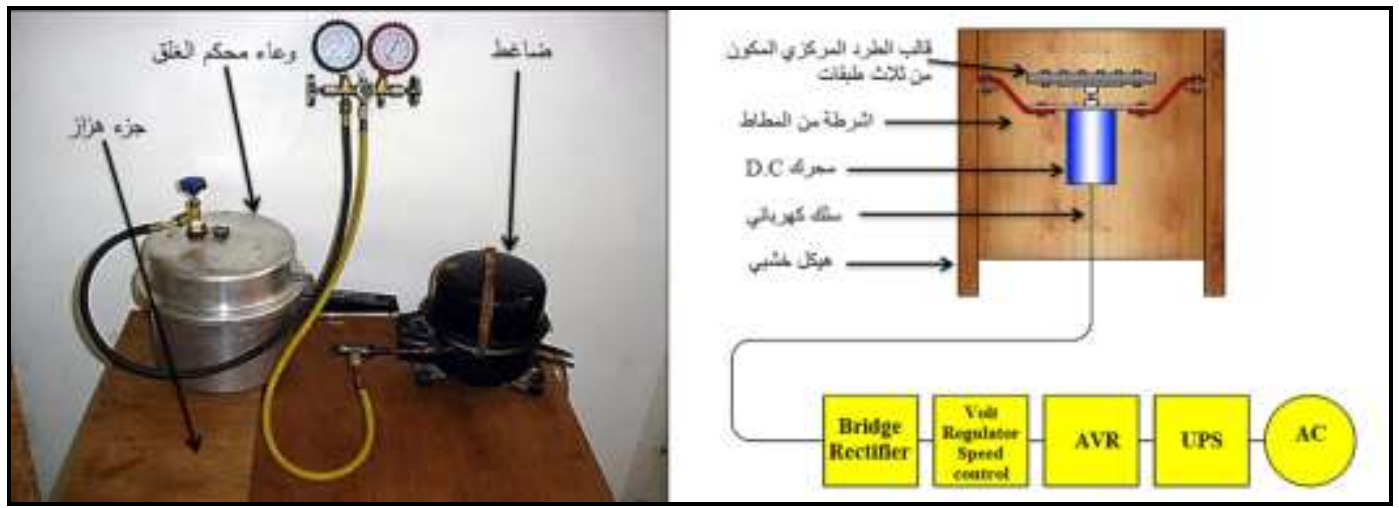

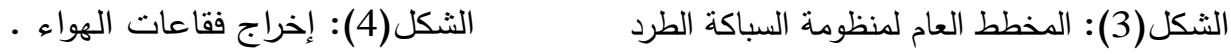

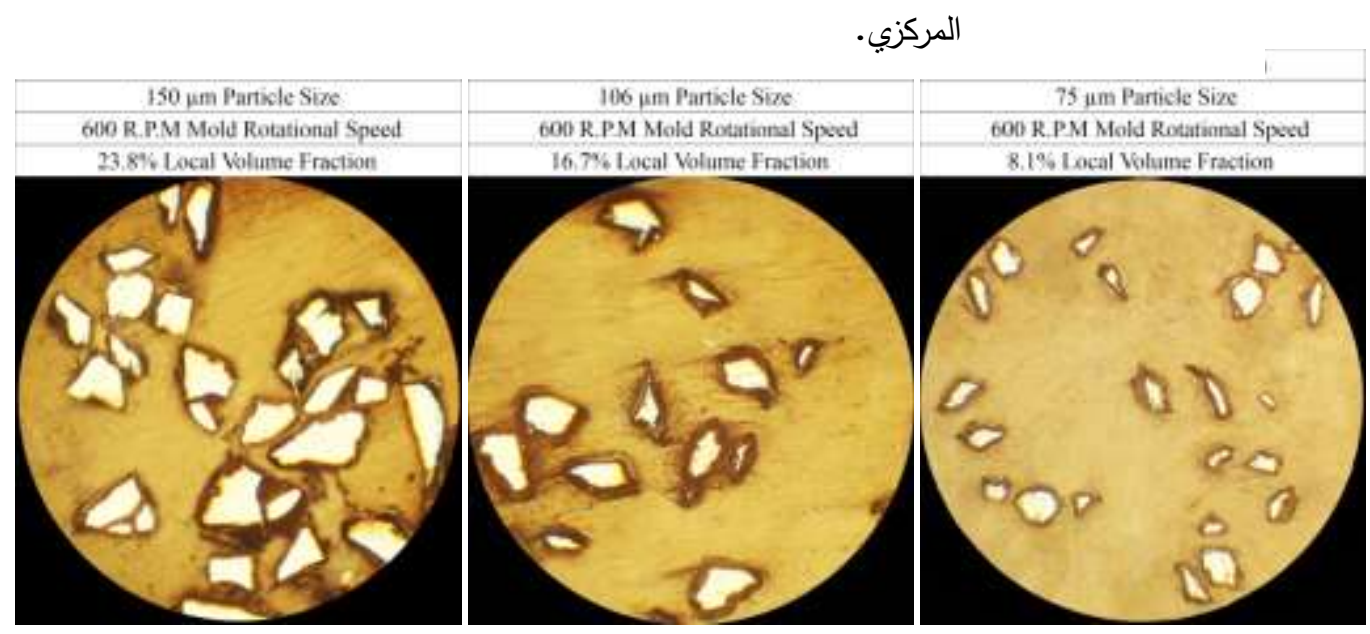

الثكل (5): البنية المجهرية (X80).

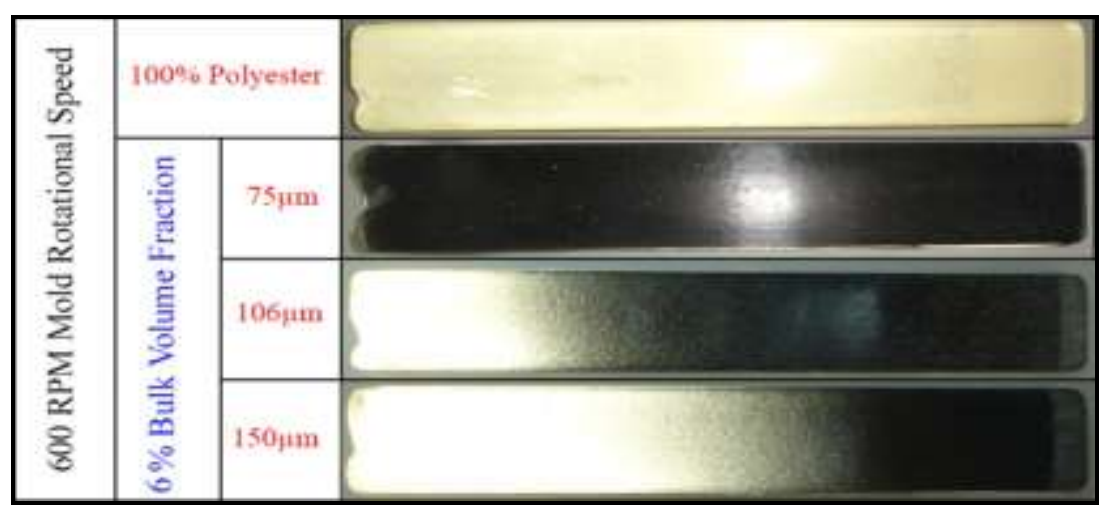

الثكل(6): نماذج المواد المتراكبة المنذرجة وظيفياً المصنعة.

ولغرض ايجاد الكسر الحجمي الموضعي للاقائق للنماذج المصنعة تم تحديد نقاط على طول

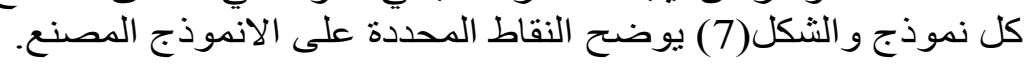

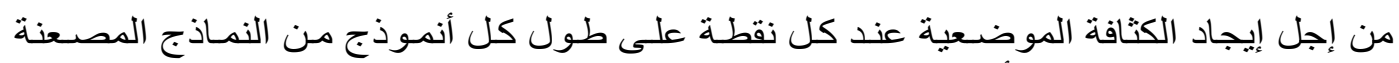

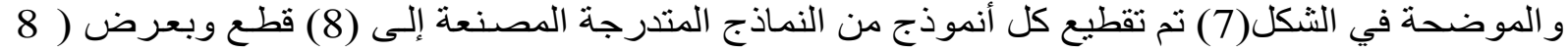




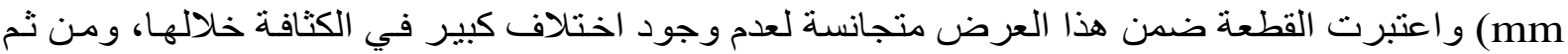

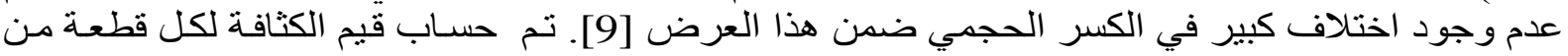

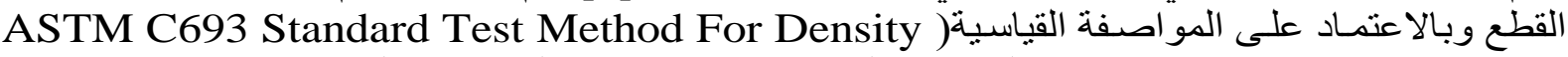

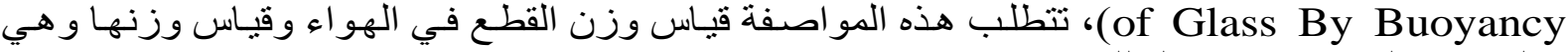

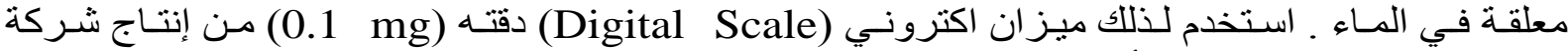
الألمانية موديله (Denver Instrument)

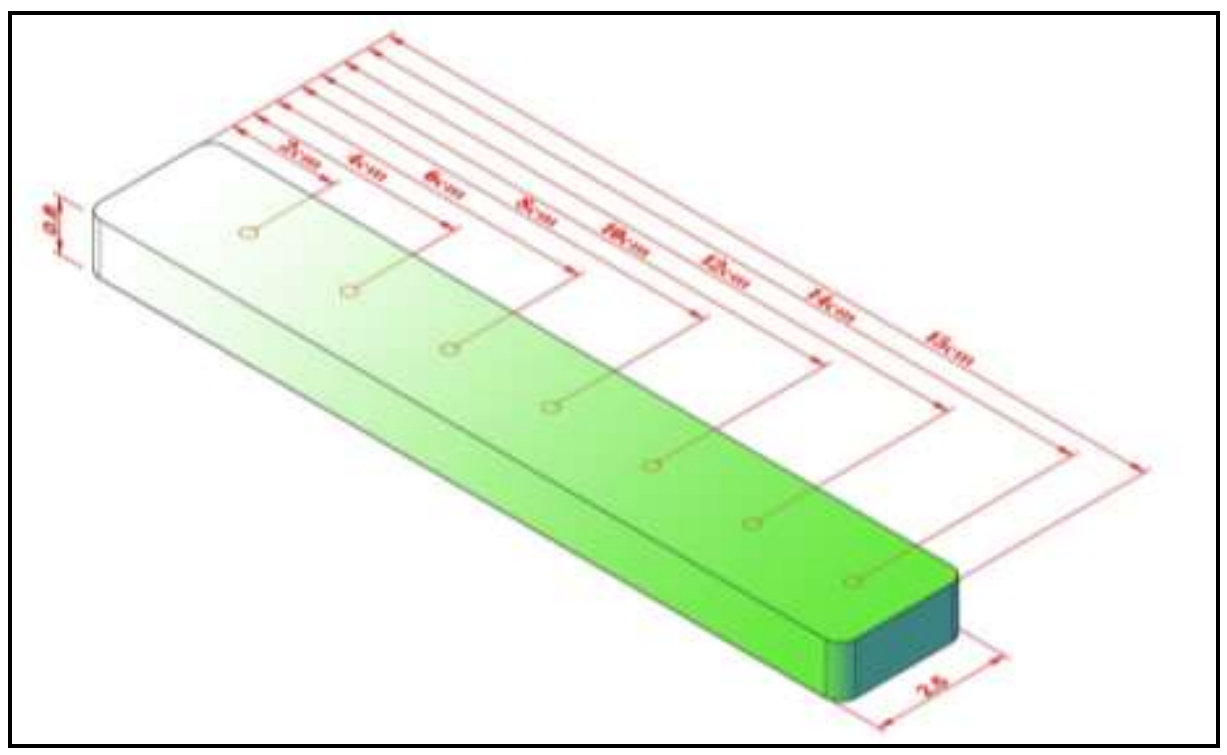

الثكل(7): النقاط المحددة على طول الانموذج المتدرج.

بعد إيجاد كثافة كل قطعة من قطع كل أنموذج متدر ج تم حساب الكسر الحجمي للدقائق كربيد

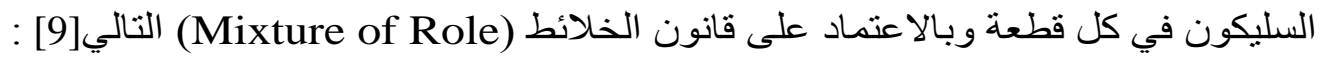

$\rho_{c}=V_{m} \rho_{m}+V_{p} \rho_{p}$

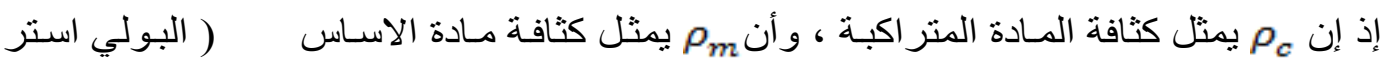

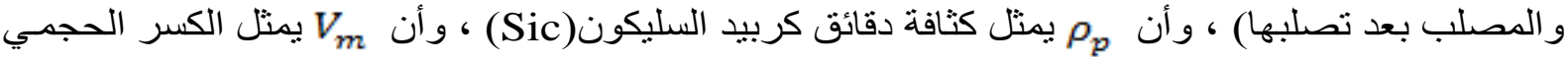

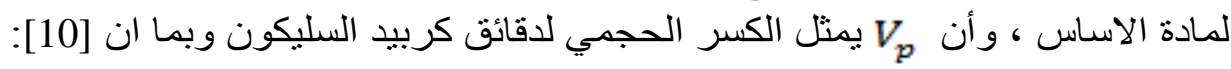

$V_{m}+V_{p}=1$

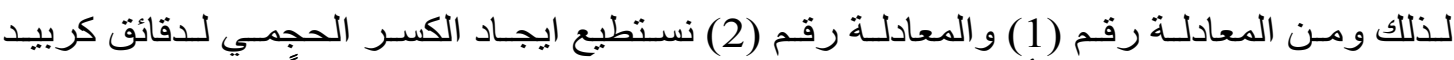

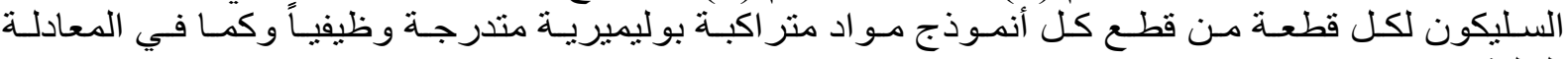

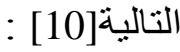

$V_{p}=\frac{\rho_{c}-\rho_{m}}{\rho_{p}-\rho_{m}} \times 100 \%$

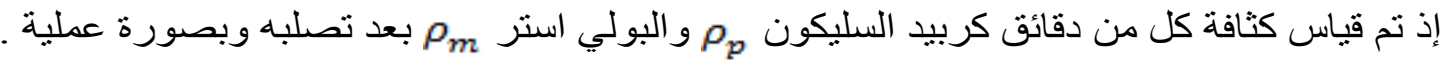




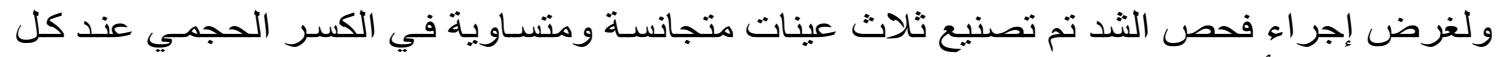

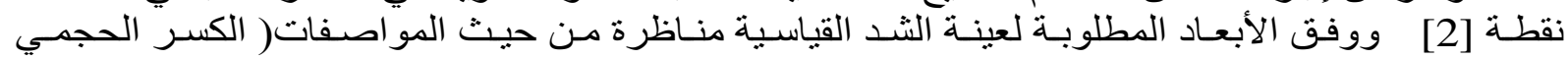

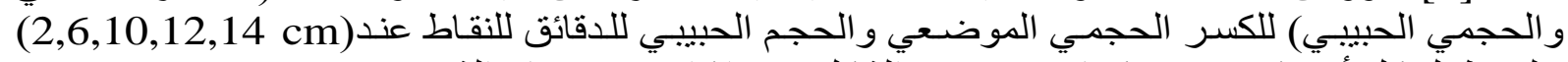

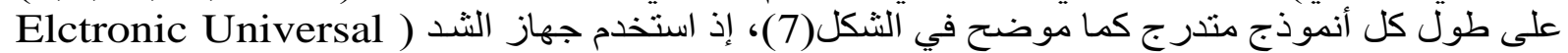

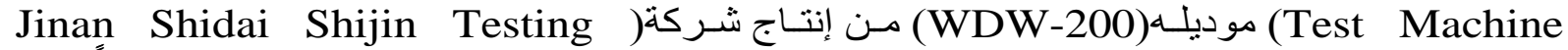
(3mm/min) الصينية وتم سحب العينات بسر عة مقدار هاد على (Machine Group Co., Ltd. ASTM D638-02a Standard Test Method for Tensile Properties of ( المو اصفة القياسية

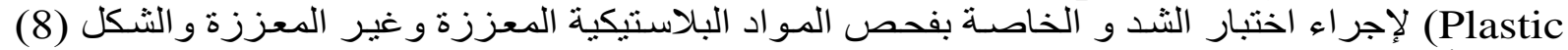
يوضح أبعاد عينة الثد وفت الثتار هذه المو اصفة [11]

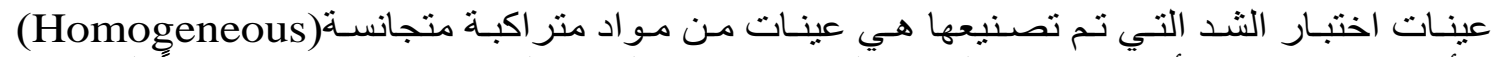

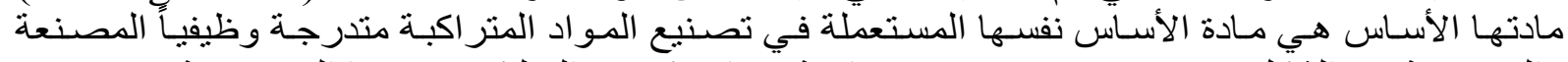

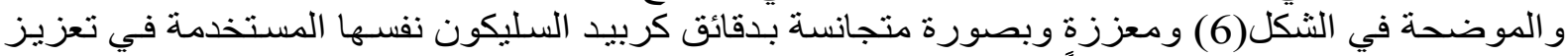

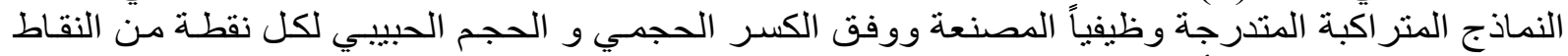

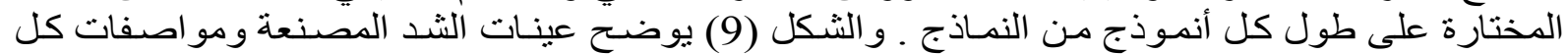
عينة بعد اكتمال تصنيعها و إخر اجها من الفرن الكهربائي .

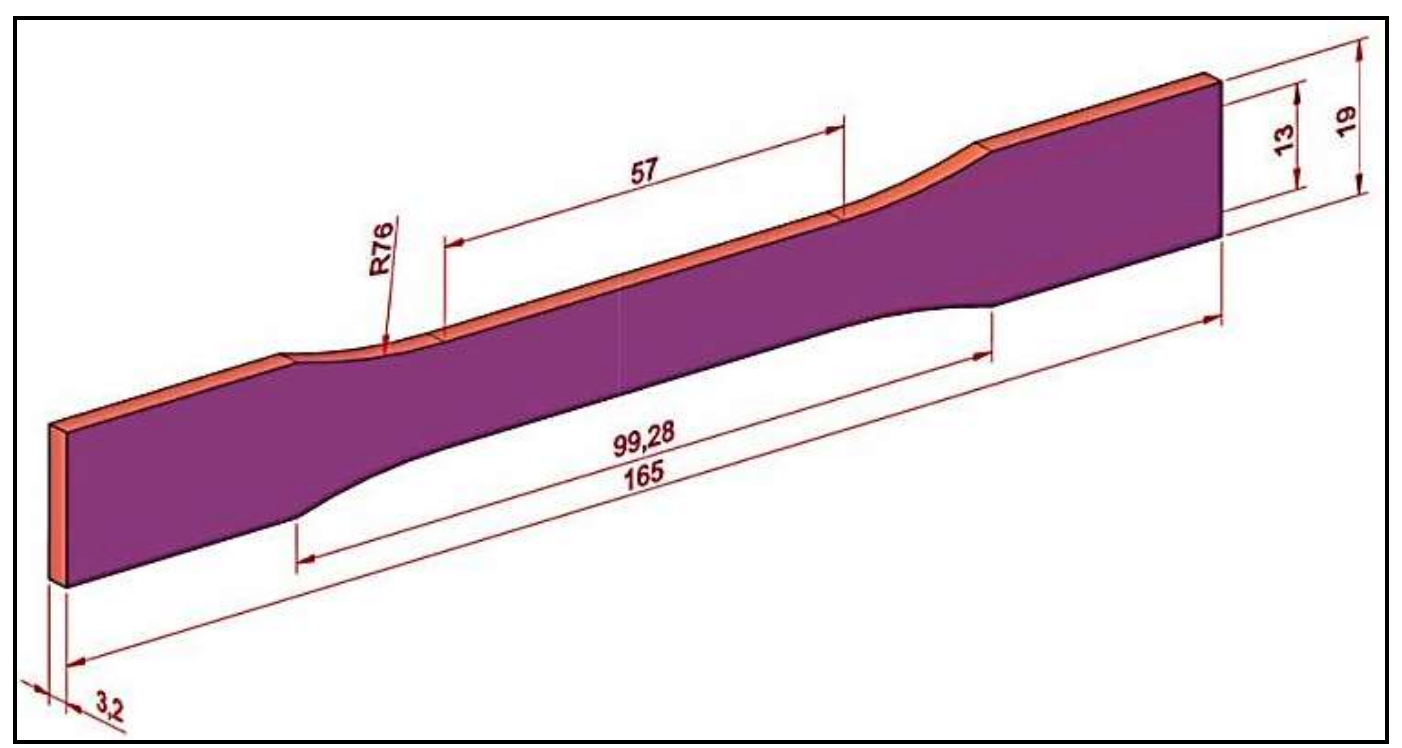

الثكل(8): ابعاد عينة الثد القياسية[11].

تم إجر اء اختبار الثتد للعينات المتجانسة والموضحة في الثنكل(9) و وايجاد معامل المرونـة لكل عينـة

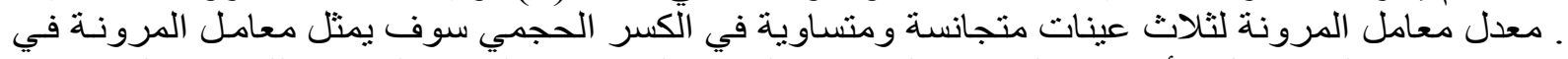

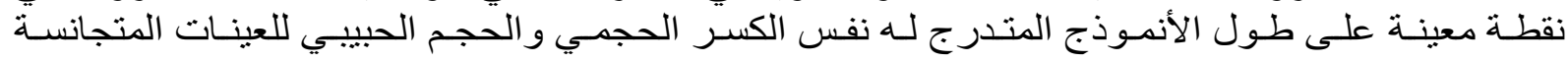



Al-Rafidain Engineering
Vol.22
No. 4
May 2014
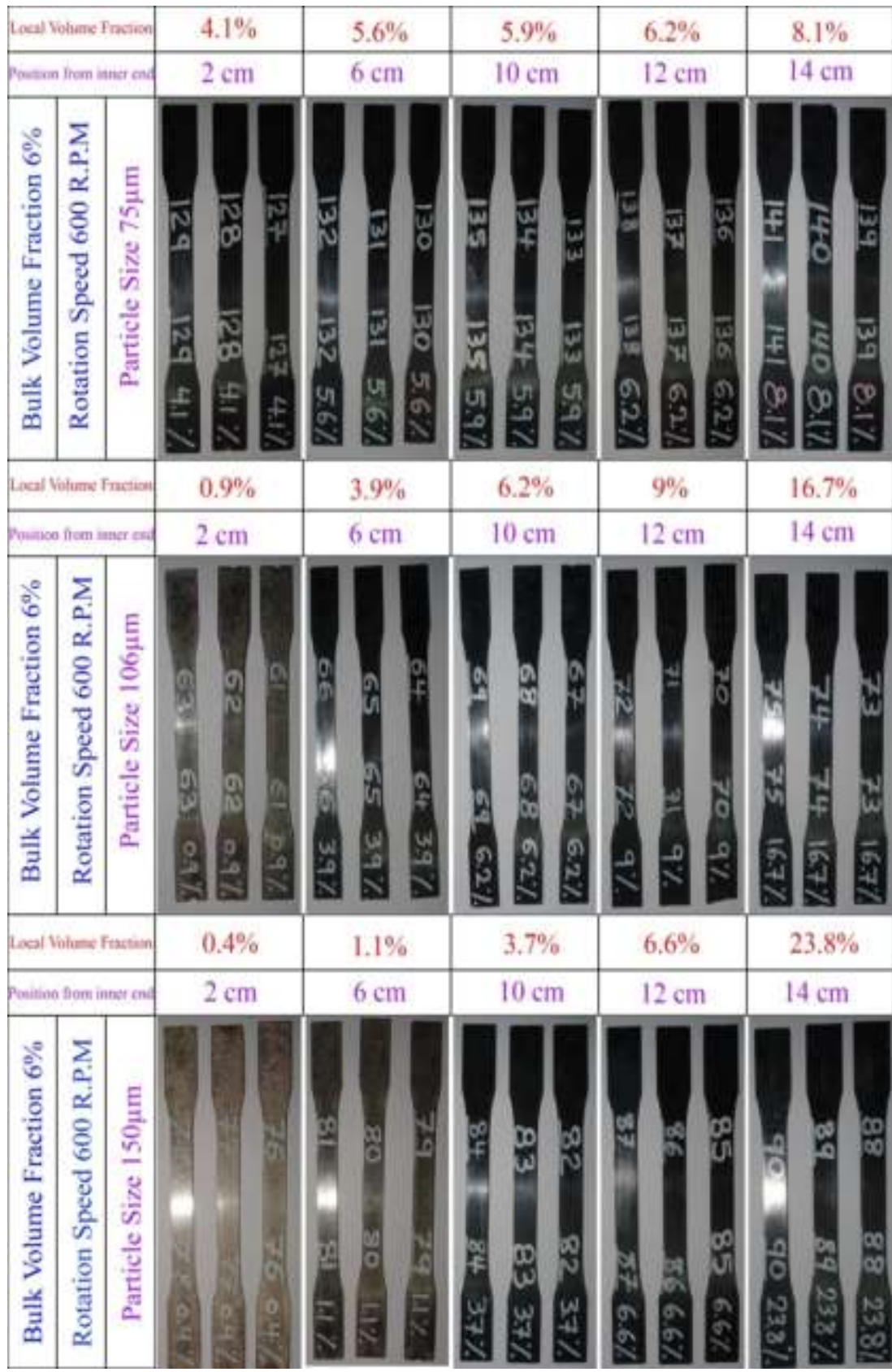

الثكل(9): صور فوتوغر افية لعينات الثد المتجانسة عند السرعة (600 RPM).

3.النتائسج والمناقشة:

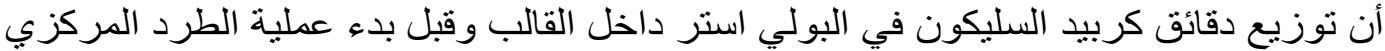

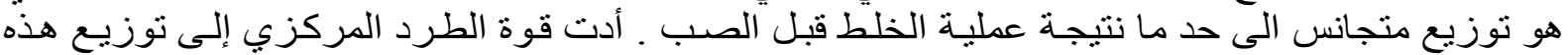

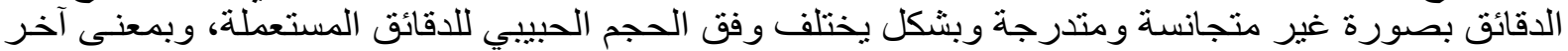

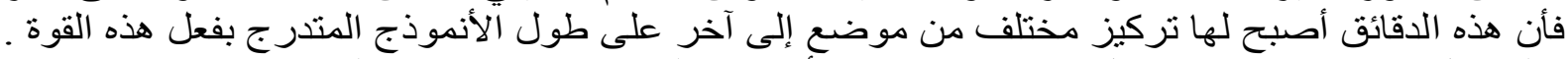

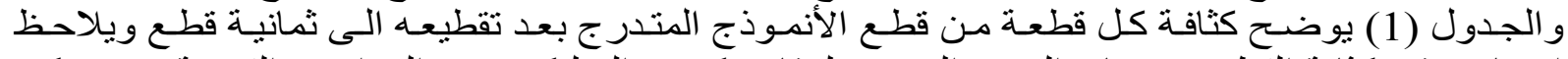

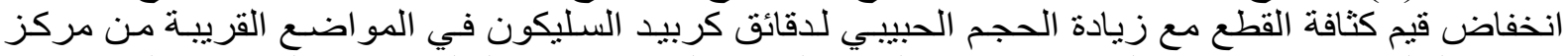
دور ان القالب و ارتفاع كثافة القطع مع زيادة الحجم الحبيبي لدقائق كربيد السليكون في المو اضع البع البعيدة عن من 


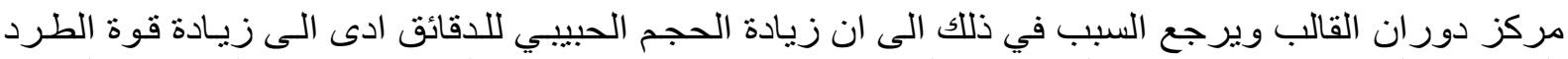

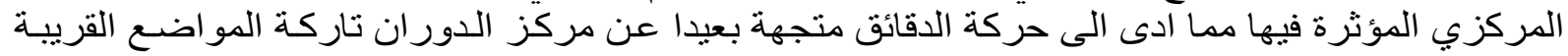

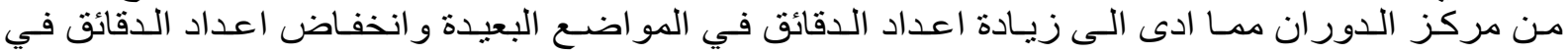

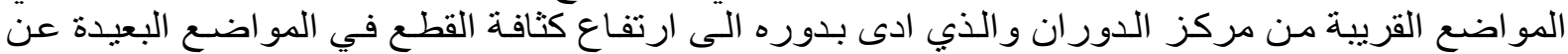

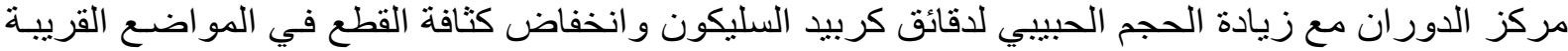

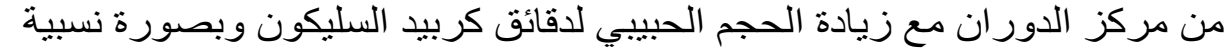

الجدول(1):كثافة قطع نماذج المو اد المتر اكبة المتدرجة وظيفياً.

\begin{tabular}{|c|c|c|c|c|c|c|c|c|c|}
\hline & distance $(\mathrm{cm})$ & 2 & 4 & 6 & 8 & 10 & 12 & 14 & 15 \\
\hline \multirow{4}{*}{ 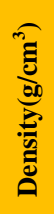 } & $\begin{array}{c}100 \% \\
\text { Polyester }\end{array}$ & 1.2425 & 1.2425 & 1.2425 & 1.2425 & 1.2425 & 1.2425 & 1.2425 & 1.2425 \\
\hline & $6 \% 75 \mu \mathrm{m}$ & 1.3201 & 1.3476 & 1.3501 & 1.3529 & 1.3548 & 1.3613 & 1.3888 & 1.5688 \\
\hline & $6 \% 106 \mu \mathrm{m}$ & 1.2572 & 1.2827 & 1.3212 & 1.3443 & 1.3597 & 1.3936 & 1.5303 & 2.0591 \\
\hline & $6 \% 150 \mu \mathrm{m}$ & 1.2513 & 1.2525 & 1.2619 & 1.2807 & 1.3117 & 1.3695 & 1.7056 & 2.1062 \\
\hline
\end{tabular}

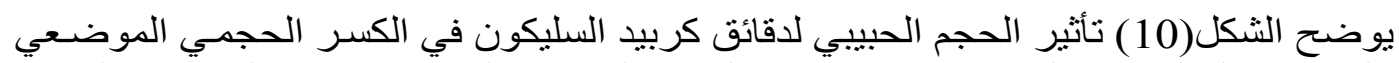

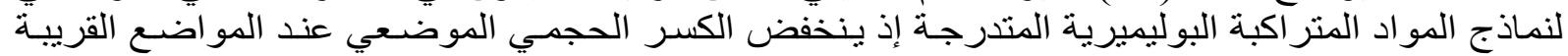

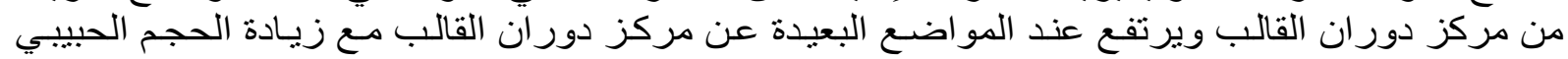

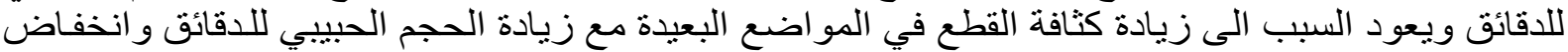

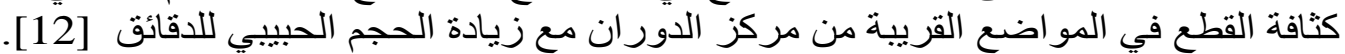

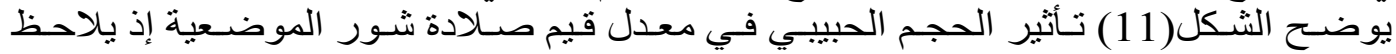

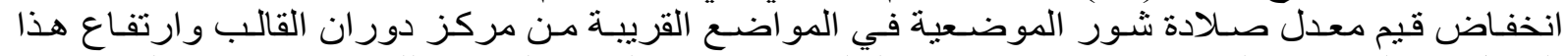

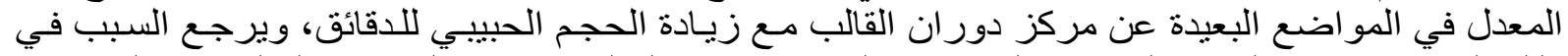

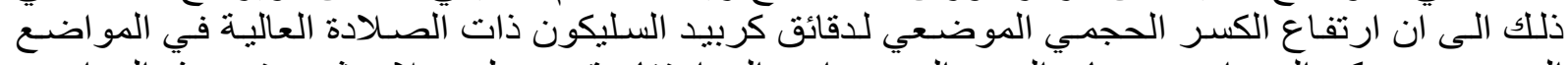

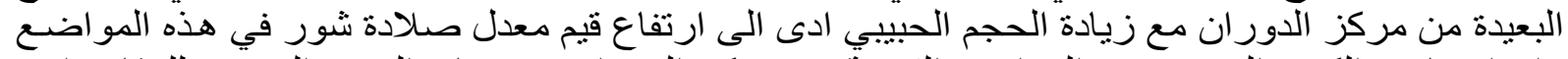

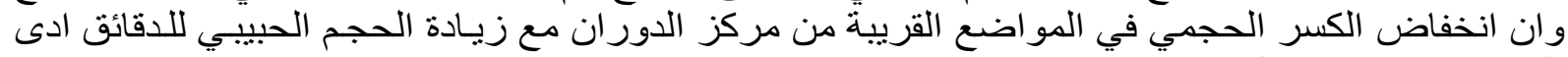

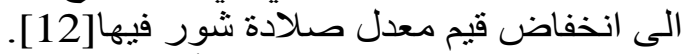

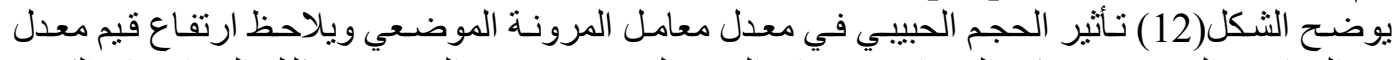

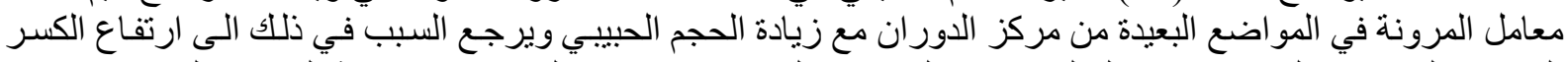

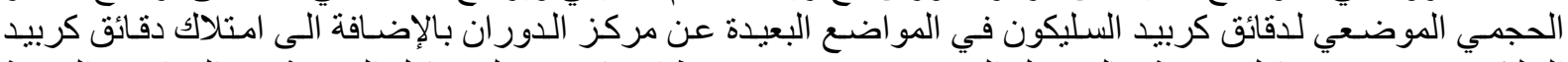

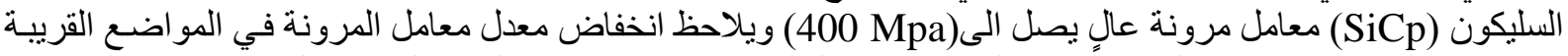

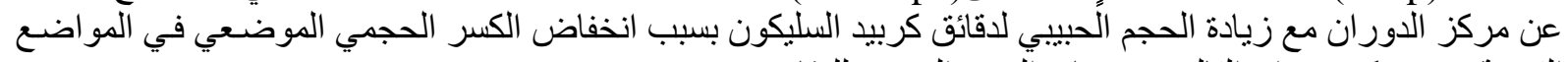

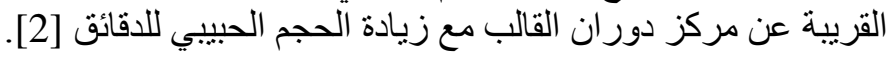

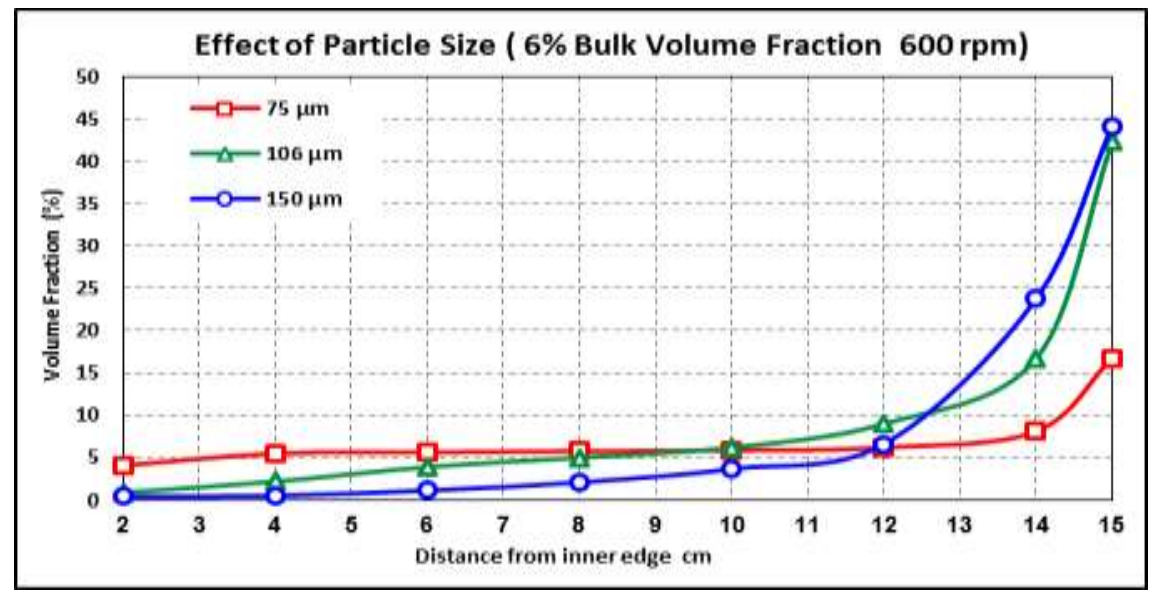

الثكل(10): تأثثير الحجمي الحبيبي في الكسر الحجمي الموضعي. 

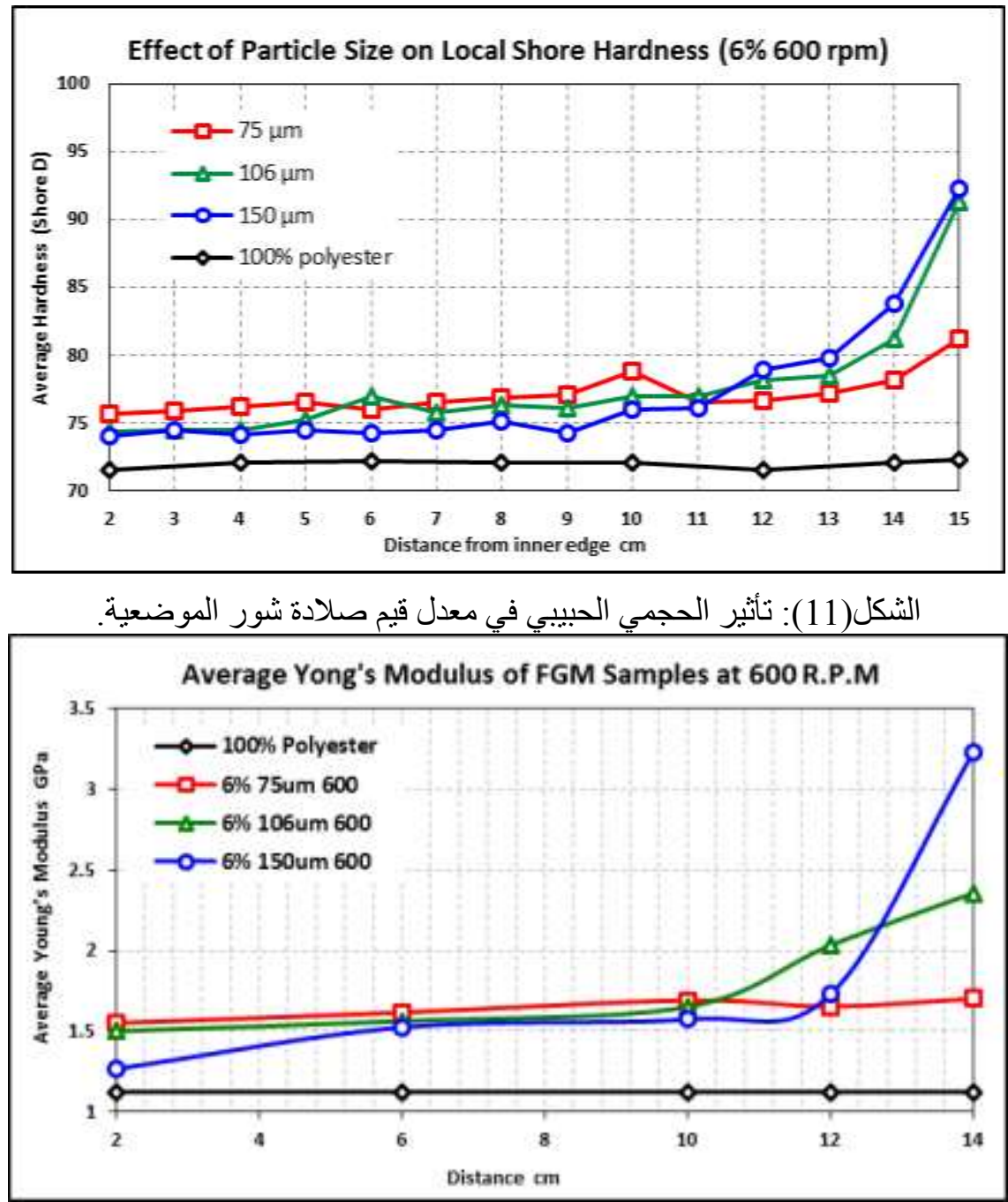

الثكل(12): نأثير الحجم الحبيبي في معدل معامل المرونة لنماذج مو اد متر اكبة متدرجة وظيفياً.

1. تتخفض قيم الكسر الحجمي الموضعي والصلادة ومعامل مرونة الثند الموضعي مع زيادة الحجم الحبيبي في المواضع

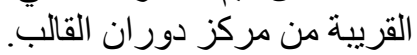

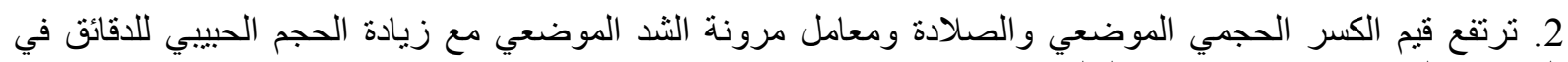

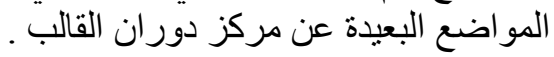

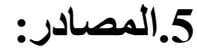

1 J. Stabik, A. Dybowska*, M. Chomiak ," Polymer composites filled with powders as polymer graded materials ", Journal of Achievements in Materials and Manufacturing Engineering, Volume 43 ,Issue 1, November 2010 ,153-161.

2 R. J. Butcher, C.-E. Rousseau and H. V. Ttippur," A functionally graded particulate composite:preparation, measurements and failure analysis", Elsevier Science, Volume 47, Issue 1, 1999, 259-268.

3 S. M. Elia ,"Studying the Effect of Adding Sea Nodules Powders on Flexural Strength 
and Hardness of Unsaturated Polyester Resin",Eng. \& Tech. Journal, Volume 29, Issue $13,2011,2807-2817$.

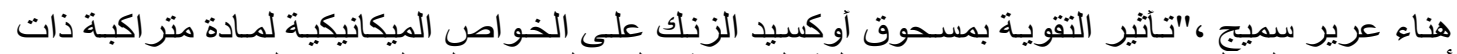

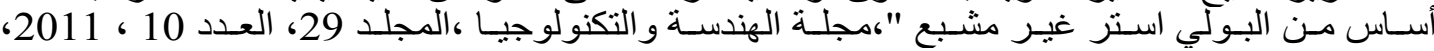

P. R. Marur ,H. V. Tippur ,"Evaluation of Mechanical Properties of Functionally Graded Materials", Journal of Testing and Evaluating, JTEVA, Volume 26, Issue 6, November 1998,539-545.

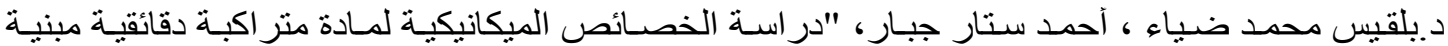

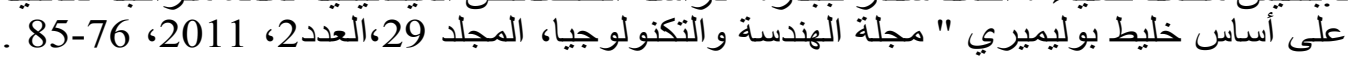

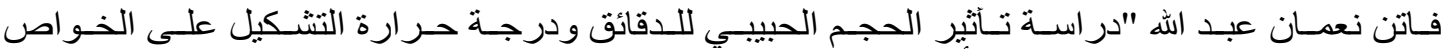

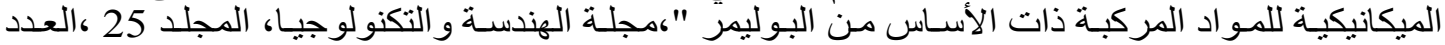

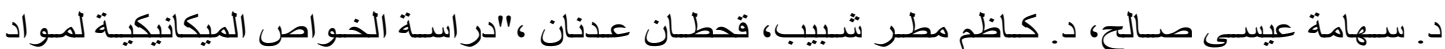

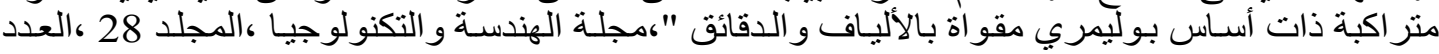

$$
\text { .93-81، 2010، }
$$

9 N. Gupta , P. K. Rohatgi , T. Matsunaga, ,"Compressive and ultrasonic properties of polyester/fly ash composites", J Mater Sci ,44, January 2009,1485-1493.

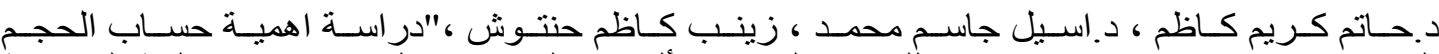

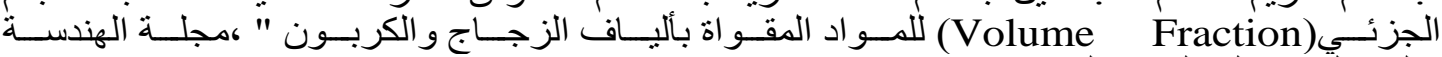
و التكنولوجيا،المجلد29،العدد4 ، 2011، 195-205.

11 ASTM D 638 - 02a .2003.Standard Test Method for Tensile Properties of Plastics,Annual book of ASTM standards,Vol.08.01,American Society for Testing and Materials ,Philadelphia.

د. نوال عزت عبد اللطيف، سمير فياض، محسن طالب "در اسة خواص المواد المتر الكبة المبة المنتجة بطريقة السباكة

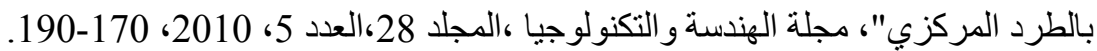

تم اجراء البحث في كلية ألهندة = جامعة ألموصل 